\title{
Effect of a Three-Week Inpatient Rehabilitation Program on 544 Consecutive Patients with Very Severe COPD: A Retrospective Analysis
}

\author{
Timm Greulich ${ }^{a}$ Andreas Rembert Koczulla ${ }^{a} \quad$ Christoph Nell ${ }^{a}$ \\ Katharina Kehr ${ }^{a} \quad$ Claus F. Vogelmeier ${ }^{a}$ Dragan Stojanovic $^{b}$ \\ Michael Wittmann ${ }^{b}$ Konrad Schultz ${ }^{\text {b }}$ \\ a Pulmonary and Critical Care Medicine, Department of Medicine, University Medical Center Giessen and Marburg, \\ Philipps-Universität Marburg, Marburg, and ${ }^{b}$ Center for Rehabilitation, Pulmonology and Orthopedics, Clinic \\ Bad Reichenhall, Bad Reichenhall, Germany
}

\section{Key Words}

Pulmonary rehabilitation - Chronic obstructive pulmonary disease · Exercise capacity · Quality of life · Dyspnea

\begin{abstract}
Background: Pulmonary rehabilitation improves exercise capacity, symptoms, and quality of life in chronic obstructive pulmonary disease (COPD) patients, and is therefore recommended in all stages of the disease. However, there are insufficient data on patients with very severe disease. Objective: To describe the effect of an in-house multidisciplinary pulmonary rehabilitation program on patients with very severe COPD. Methods: We performed a retrospective analysis of 544 consecutive patients with very severe COPD $\left(F V_{1} 0.97 \pm 0.26 \mathrm{I}\right)$ that underwent an in-house pulmonary rehabilitation program (23.44 \pm 4.97 days). The studied outcome parameters were the 6-min walk test (6-MWT), health-related quality of life as analyzed by the COPD Assessment Test (CAT) and a dyspnea score [modified Medical Research Council (mMRC) scale], and lung function [forced expiratory volume in $1 \mathrm{~s}\left(\mathrm{FEV}_{1}\right)$ and residual volume (RV)]. Results: We found significant improvements regard-
\end{abstract}

ing 6-MWT scores (from $321.93 \pm 115.67$ to $365.82 \pm 111.79$ $\mathrm{m} ; \mathrm{p}<0.001$ ), CAT scores (from $23.21 \pm 6.75$ to $19.57 \pm 7.35$; $\mathrm{p}<0.001$ ), mMRC scale scores (from $3.17 \pm 1.14$ to $2.81 \pm$ 1.22; $\mathrm{p}<0.001$ ), and $\mathrm{FEV}_{1}$ (from $0.97 \pm 0.26$ to $1.08 \pm 0.33$ l; $p<0.001)$. A number of baseline variables were significantly correlated with the improvements that occurred during the program $(\Delta)$ : baseline 6-MWT with $\triangle 6-M W T(r=-0.316$; $p<0.001)$, baseline CAT with $\Delta$ CAT $(r=-0.302 ; p<0.001)$, baseline mMRC with $\triangle \mathrm{mMRC}(\mathrm{r}=-0.444 ; \mathrm{p}<0.001)$, and baseline RV with $\Delta R V(r=-0.284 ; p<0.001)$, demonstrating that improvements were more pronounced in patients with worse baseline characteristics. Patients on long-term oxygen therapy (LTOT) exhibited significantly greater improvements regarding CAT than patients not on LTOT. Conclusion: Patients with very severe COPD exhibit clinically meaningful improvements when undergoing pulmonary rehabilitation.

(c) 2015 S. Karger AG, Basel

T.G. and A.R.K. contributed as first, and M.W. and K.S. contributed as last authors. T.G., A.R.K., C.N., K.K., and C.F.V. are members of the German Center for Lung Research (DZL).

\section{KARGER 125}

C 2015 S. Karger AG, Base

0025-7931/15/0904-0287\$39.50/0

E-Mail karger@karger.com

www.karger.com/res
Dr. Konrad Schultz, MD

Clinic Bad Reichenhall, Center for Rehabilitation, Pulmonology and Orthopedics Salzburger Strasse 8

DE-83435 Bad Reichenhall (Germany)

E-Mail konrad.schultz@klinik-bad-reichenhall.de 


\section{Introduction}

Chronic obstructive pulmonary disease (COPD) is a common preventable and treatable disease characterized by a usually progressive airflow limitation that is accompanied by deteriorations in exercise capacity and quality of life [1]. Therapeutic options include pharmacotherapy as well as nonpharmacological interventions (smoking cessation, pulmonary rehabilitation, oxygen therapy, ventilatory support, surgical treatment, and palliative care treatment) [1].

It has been demonstrated that pulmonary rehabilitation improves exercise performance, dyspnea, and quality of life, reduces the effects of acute exacerbations, and prolongs the time to the next exacerbation [2-4]. Current international guidelines recommend a minimum length of 6 weeks for a pulmonary rehabilitation program, indicating a higher efficacy of programs with a longer duration [5-7]. However, in some countries (as in Germany) the length of the program is limited to 3 weeks by the majority of insurance companies.

While an increasing number of clinical studies on pulmonary rehabilitation in COPD have recently been published [8], studies on very severe COPD patients are scarce $[9,10]$. With our study we wanted to gain more information about the efficacy of a 3-week multidisciplinary in-house rehabilitation program for very severe COPD patients. Therefore, we performed a retrospective analysis of 544 consecutive very severe COPD patients [forced expiratory volume in $1 \mathrm{~s}\left(\mathrm{FEV}_{1}\right) 0.97 \pm 0.26 \mathrm{l}$ ] that underwent an in-house pulmonary rehabilitation program (22.96 \pm 4.9 days) in our inpatient rehabilitation center, which specializes in pulmonary rehabilitation for patients with chronic lung diseases.

\section{Subjects and Methods}

\section{Patient Population}

Between January 1, 2010, and December 31, 2012, we included 544 consecutive patients with stage IV COPD (defined by postbronchodilator $\mathrm{FEV}_{1}<30 \%$ predicted or by $\mathrm{FEV}_{1}<50 \%$ predicted with $\mathrm{PaO}_{2}<60 \mathrm{~mm} \mathrm{Hg}$ [11]) measured at baseline. The baseline characteristics can be found in table 1 .

\section{Intervention}

An intensive 3-week full-day inpatient rehabilitation program was conducted. It was possible to apply for an extension week, which increased the mean duration to $22.96 \pm 4.97$ days. The relevant nondrug therapy components were tailored to the patients' individual needs; they included: exercise training (endurance and strength training; aiming at a workload of $60-80 \%$ of the personal maximum, 1-2 sessions daily, with a duration of $1.5 \mathrm{~h}, 5$ days a week, based on
Table 1. Patient characteristics at baseline

\begin{tabular}{lc}
\hline Age, years & $57.23 \pm 6.82$ \\
Gender, $\mathrm{n}(\%)$ & $318(58.5)$ \\
$\quad$ Male & $226(41.5)$ \\
$\quad$ Female & $24.33 \pm 5.7$ \\
BMI & \\
Active smoking & $154(28.3)$ \\
$\quad$ Number (\%) & $53.2 \pm 23.2$ \\
$\quad$ Pack-years & \\
Ex-smokers & $375(68.9)$ \\
$\quad$ Number $(\%)$ & $47.6 \pm 25.34$ \\
$\quad$ Pack-years & $15(2.8)$ \\
Never-smokers, $\mathrm{n}(\%)$ & $0.97 \pm 0.26$ \\
Post-BD FEV ${ }_{1}$ absolute, & $34.19 \pm 7.67$ \\
Post-BD FEV,$\%$ predicted & $4.8 \pm 1.22$ \\
RV, l & $95.27 \pm 2.67$ \\
SO ${ }_{2}, \%$ & $328(60.29)$ \\
On LTOT, n (\%) & $321.93 \pm 115.67$ \\
6-MWT, m & $23.21 \pm 6.75$ \\
CAT score & $3.17 \pm 1.14$ \\
mMRC scale score & $4.68 \pm 1.95$ \\
Borg scale score &
\end{tabular}

Data are displayed as means \pm SD unless indicated otherwise. $\mathrm{BD}=$ bronchodilator; $\mathrm{BMI}=$ body mass index; $\mathrm{SO}_{2}=$ oxygen saturation.

current recommendations); inspiratory muscle training (where clinically indicated; $7 \times 2$ min a day, 7 days a week, at high intensity); intensive patient education; respiratory physiotherapy with emphasis on breathlessness management advice ( 5 days a week); bronchus drainage measures (where clinically indicated; $30 \mathrm{~min}$ a day, 7 days a week); balneophysical measures; tobacco cessation counseling; initiation of long-term oxygen therapy (LTOT) and/or noninvasive ventilation; psychological support, and nutrition counseling.

\section{Assessments}

The following assessments were performed at least twice (at admission and discharge): lung function testing (MasterLab; Viasys Jaeger, Höchberg, Germany) according to ATS/ERS guidelines [12]; a 6-min walk test (6-MWT) [13] with a dyspnea evaluation via the Borg scale [14], COPD Assessment Test (CAT) [15], and modified Medical Research Council (mMRC) scale $[1,16]$.

\section{Statistics and Data Analysis}

For comparisons of data at the beginning and at the end of rehabilitation, the Wilcoxon rank-sum test for paired samples was used. To determine relationships between the variables, the Spearman correlation coefficient was calculated. For comparing the two groups of 'on LTOT' and 'not on LTOT', the Mann-Whitney U test for unpaired samples was performed. In the case of ranking scale variables, the Fisher exact test was used. p values $<0.05$ were considered to be significant. For data analysis, SPSS 22 (IBM GmbH, Ehningen, Germany) and GraphPad 5.0 (GraphPad Software Inc., La Jolla, Calif., USA) were used. Ethics committee approval was obtained by the Ethics Committee of Philipps-Universität Marburg. 


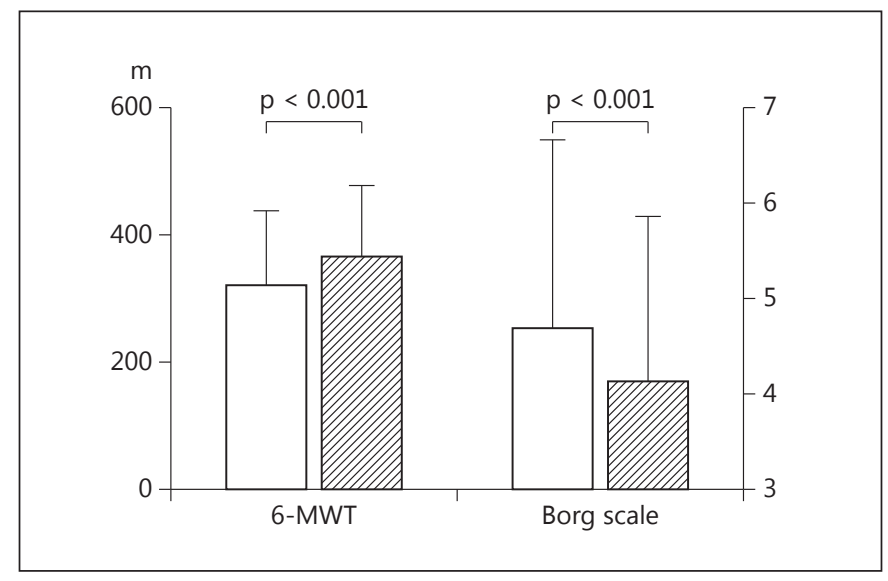

Fig. 1. Changes regarding exercise capacity (6-MWT) and exercise-related dyspnea (Borg scale; $n=428$ ). Data were analyzed at the start (white columns) and the end of the rehabilitation program (hatched columns).

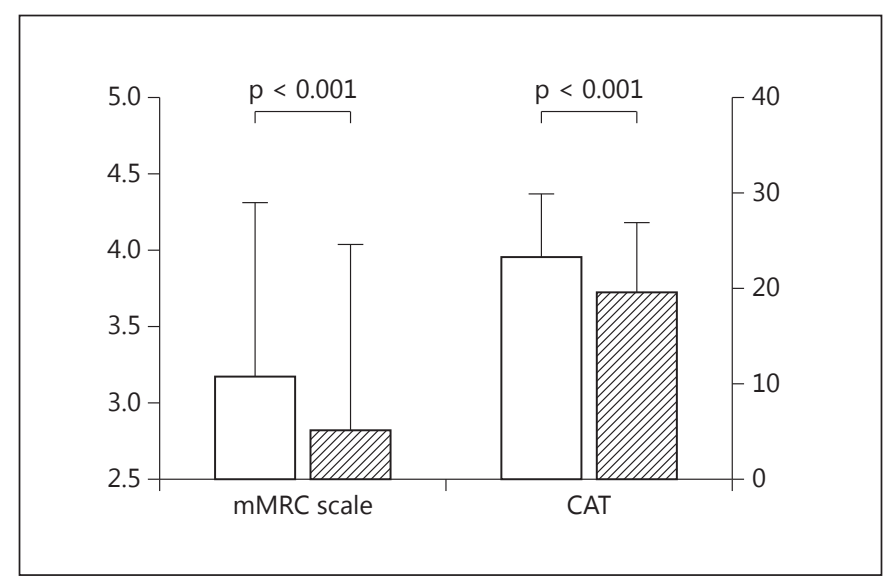

Fig. 2. Changes regarding dyspnea (mMRC scale) and health-related quality of life (CAT; $n=371)$. Data were analyzed at the start (white columns) and the end of the rehabilitation program (hatched columns).

\section{Results}

Effects of Pulmonary Rehabilitation on All Patients

Comparing exercise capacity (at admission and at discharge), we saw an increase in 6-MWT distance by 42.8 $\mathrm{m}(\mathrm{p}<0.001$; fig. 1$)$, accompanied by a reduction of exercise-related dyspnea (the Borg scale score decreased by $0.55, \mathrm{p}<0.001$; fig. 1). Dyspnea in general was improved (the mMRC scale score decreased by 0.36 units, $\mathrm{p}<0.001$; fig. 2). Furthermore, we detected a statistically significant improvement in health-related quality of life (the CAT

Inpatient Rehabilitation Program for Patients with Very Severe COPD

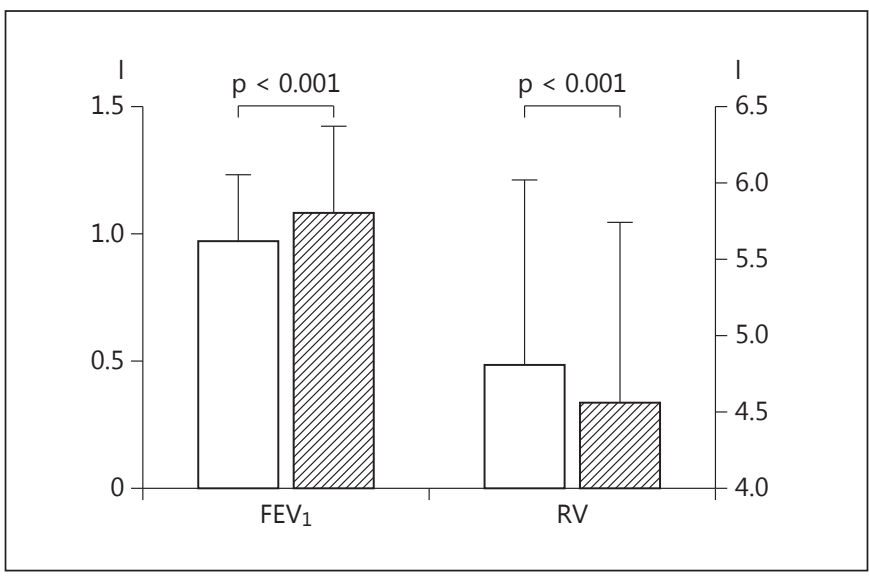

Fig. 3. Changes regarding lung function $\left(\mathrm{FEV}_{1}\right.$ and $\left.\mathrm{RV} ; \mathrm{n}=431\right)$. Data were analyzed at the start (white columns) and the end of the rehabilitation program (hatched columns).

score decreased by 3.64 units, $\mathrm{p}<0.001$; fig. 2). Comparing lung function data from the beginning and from the end of the in-house rehabilitation program, we found significant improvements in lung function (fig. 3): the FEV improved by $99 \mathrm{ml}(\mathrm{p}<0.001)$, and the residual volume (RV) decreased by $240 \mathrm{ml}(\mathrm{p}<0.001)$.

\section{Correlation between Baseline Variables and \\ Related Improvements}

When we correlated the baseline variables with the improvements that occurred during the program, we observed significant correlations ( $\mathrm{p}<0.001$ for each) between baseline 6-MWT score ( $\mathrm{r}=-0.316$; fig. $4 \mathrm{a})$, baseline mMRC scale score $(\mathrm{r}=-0.444$; fig. $4 \mathrm{~b})$, baseline CAT score $(\mathrm{r}=-0.302$; fig. $4 \mathrm{c})$, and baseline RV $(\mathrm{r}=-0.284$; fig. $4 \mathrm{~d}$ ) and the respective changes $(\Delta)$.

\section{Subgroup Analyses}

We analyzed a number of potential confounders that would affect treatment response: absence/presence of LTOT; exacerbation-related start of rehabilitation versus start from a stable state; duration of rehabilitation $(\leq 21$ vs. $>21$ days); age ( $>65$ vs. $\leq 65$ years); clinically significant improvement in the 6-MWT; smoking status, and weight (overweight vs. normal weight). The absence/presence of LTOT led to a significantly different treatment response regarding quality of life. The improvement in CAT scores was more pronounced in the group of patients on LTOT $(-4.33 \pm 5.75$ vs. $-2.68 \pm 6.17, \mathrm{p}<0.001$; online suppl. fig. 1; see www.karger.com/doi/10.1159/000436979 for all online suppl. material). Regarding the distinction be- 

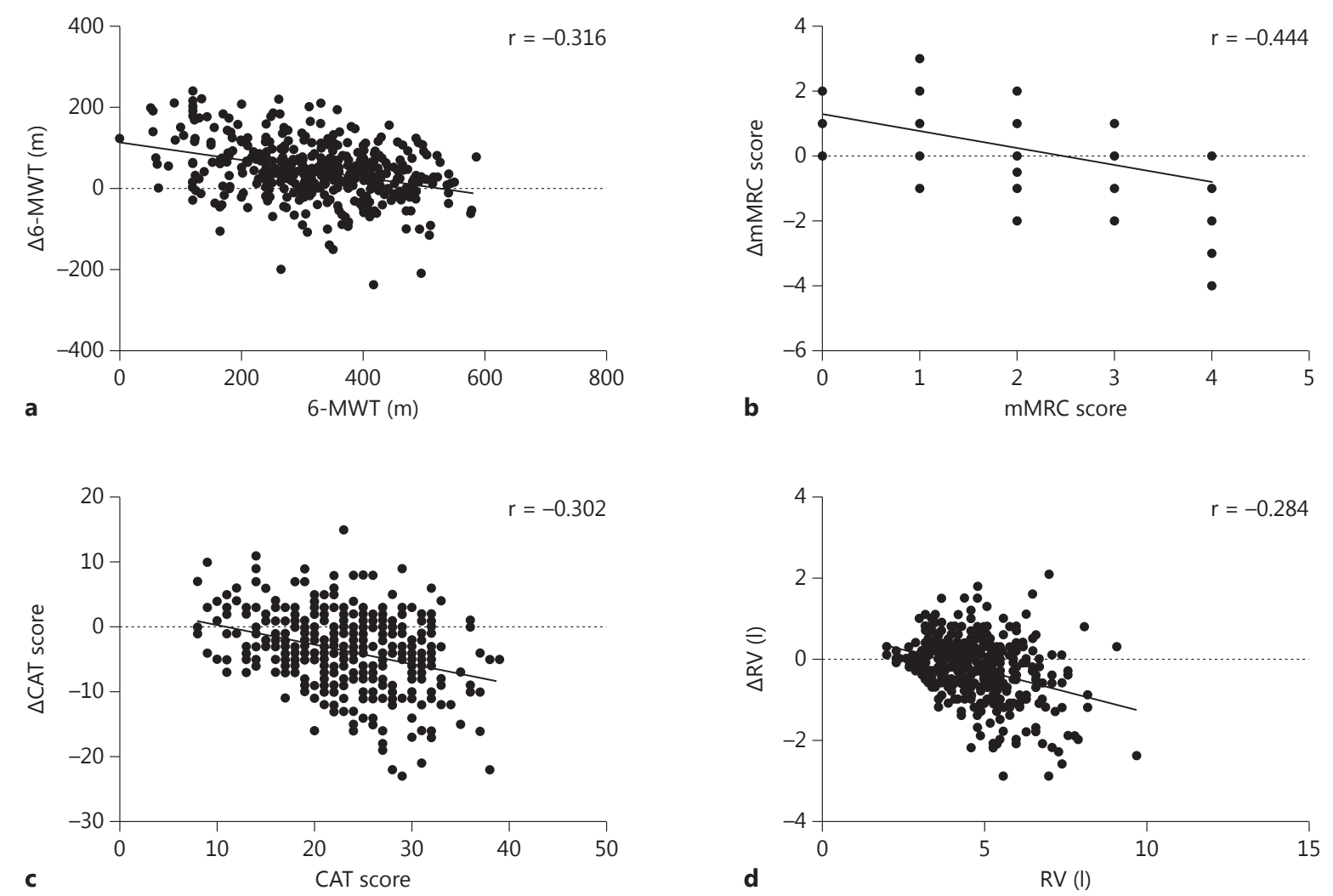

Fig. 4. Significant correlations between variables at baseline and changes $(\Delta)$ during the program. a 6-MWT $(\mathrm{n}=428)$. $\mathbf{b}$ mMRC scale $(\mathrm{n}=431)$. $\mathbf{c}$ CAT $(\mathrm{n}=371)$. $\mathbf{d} \mathrm{RV}(\mathrm{n}=428)$.

tween an exacerbation-related start of rehabilitation versus a start from a stable state, patients that were included from a stable state had a significantly higher improvement of dyspnea (mMRC scale score improvement: -0.45 $\pm \mathrm{SD}$ vs. $-0.24 \pm \mathrm{SD}, \mathrm{p}<0.05$; online suppl. fig. $2 \mathrm{e})$. Regarding duration of rehabilitation, the improvement in $\mathrm{FEV}_{1}$ was significantly higher in the group with the longer duration (140 vs. $100 \mathrm{ml}, \mathrm{p}<0.05$; online suppl. fig. 3a). The other potential confounders did not result in differential outcome parameters.

\section{Discussion}

To our knowledge, this is the first large-scale analysis demonstrating that very severe COPD patients benefit from a hospital-based 3-week training program. In 544 patients, a multimodal rehabilitation program led to significant improvements regarding exercise capacity, health-related quality of life (including dyspnea), and lung function.

In our patient cohort, the 6-MWT distance increased by an average of $42.8 \mathrm{~m}$. The minimal clinically important difference (MCID) found for severe COPD patients was $26 \mathrm{~m}$ [17]. In a randomized controlled trial of a homebased 12 -week training program involving 58 severe or very severe COPD patients, a significant increase could be demonstrated $(\mathrm{p}<0.008)[10]$. In another, nonrandomized observational study of 102 COPD patients who followed a 7 -week program of pulmonary rehabilitation, the authors came to the conclusion that patients with worse disease status (combination of lower $\mathrm{FEV}_{1}$, more hyperinflation, lower exercise capacity, and worse quadriceps force) improved most in endurance exercise capacity [18].

In addition, we found statistically significant improvements regarding dyspnea (Borg scale: -0.59 ; mMRC scale: $-0.35)$. Because the MCID has been determined at 1 unit for the Borg scale [14], these changes may not be clini- 
cally relevant. However, a similar improvement $(-0.5$ units on the Borg scale) was shown in an observational study of a 3-week outpatient pulmonary rehabilitation program for patients with COPD [19]. A subgroup analysis provided evidence that the improvement in mMRC scale score was less pronounced in patients entering pulmonary rehabilitation within 2 weeks after another hospital stay (most likely COPD exacerbation). This may be due to the fact that hospital-based treatment of an exacerbation had already led to a significant improvement of dyspnea [20] and quality of life [21] and further improvement would be difficult to achieve. Furthermore, the Borg scale score decreased despite an increasing 6-MWT distance, suggesting that at an equal distance the Borg scale score would have been even better.

The patients in our observational cohort improved significantly regarding quality of life (CAT score: -3.64). As the MCID for the CAT score has recently been defined to be 2 units [22], the result should be seen as clinically meaningful.

We demonstrated an increase in post-bronchodilator $\mathrm{FEV}_{1}$ by approximately $100 \mathrm{ml}$; this was higher in the group of patients that participated $>21$ days. According to the ATS/ERS task force on COPD outcomes, a difference of $100-140 \mathrm{ml}$ is considered as the MCID [23]. There is little evidence in the literature that a short-term training program improves lung function, especially in very severe COPD patients. However, there is evidence that longterm pulmonary rehabilitation inhibits the lung's functional decline in moderate-to-severe COPD patients [24].

A correlation analysis revealed that the more severe COPD patients (higher RV, shorter 6-MWT distance, higher CAT score, higher Borg scale score, and higher mMRC scale score) achieved more substantial improvements. While some studies showed that baseline characteristics cannot identify pulmonary rehabilitation responders [25], a number of other studies support the hypothesis that poor baseline characteristics tend to result in better improvements: Zanini et al. [26] retrospectively conducted a logistic regression analysis to detect predictors of success of a 3-week pulmonary rehabilitation program in 75 COPD patients and found that poor lung function $\left(\mathrm{FEV}_{1}<50 \%\right)$ was predictive of rehabilitation success in this small group of heterogeneous patients. Furthermore, a lower baseline arterial partial oxygen pressure [27] and poorer health status [28] appear to be predictors of success in pulmonary rehabilitation. Taken together, the available data support the recommendations for even including very severe COPD patients into pulmonary rehabilitation programs. We further confirmed this by dem- onstrating that patients on LTOT (compared to those not on LTOT) had a greater benefit regarding disease-related quality of life (online suppl. fig. 1).

We think that the above-mentioned results are especially noteworthy because the mean duration of the program was only 3 weeks ( $23.44 \pm 4.97$ days). Using such a short duration does not follow recent international guidelines (which would advise $\geq 6$ weeks) [1], but it does follow national legal requirements and reflects daily practice in countries in which a longer program would not be covered by insurance companies (as is the case in Germany). The study design (missing a control arm with a longer program duration) does not allow us to draw conclusions about the relative efficacy of various durations of the program, but according to the literature, even stronger effects could be expected with a longer duration [5-7]. Our subgroup analysis comparing $\leq 21$ days of duration with $>21$ days of duration yielded very similar effects for both groups (online suppl. fig. 3 ) with a significant difference in improvement only regarding $\mathrm{FEV}_{1}$.

The study has significant limitations. Although we looked at a high number of patients, the retrospective design needs confirmation by prospective studies. The lack of a control group makes it impossible to exclude confounding biases. Since there are clear recommendations in current guidelines $[8,29]$, it may be difficult to withhold rehabilitation, including physical exercises, from this patient group. Furthermore, it seems very unlikely that very severe COPD patients would improve over time without further treatment. The observed effect may also be attributed to optimization of the inhalation therapy (pharmacotherapy, inhalation technique, or adherence). Although our database did not include medication at an individual level, it may be assumed that up to $60 \%$ of the patients had been on triple therapy before, as demonstrated in a large noninterventional survey of 3,818 COPD patients across Europe [30].

In summary, to our knowledge this is the first largescale analysis of very severe COPD patients undergoing an intensive 3-week hospital-based rehabilitation program. The observed benefits should encourage physicians to follow current guidelines to include COPD patients of all stages in structured rehabilitation programs. With this report, we strengthen the data foundation for this specific patient subgroup significantly.

\section{Financial Disclosure and Conflicts of Interest}

No conflict of interest has to be acknowledged.
Inpatient Rehabilitation Program for Patients with Very Severe COPD 


\section{References}

1 Vestbo J, Hurd SS, Agustí AG, Jones PW, Vogelmeier C, Anzueto A, Barnes PJ, Fabbri LM, Martinez FJ, Nishimura M, Stockley RA, Sin DD, Rodriguez-Roisin R: Global strategy for the diagnosis, management, and prevention of chronic obstructive pulmonary disease: GOLD executive summary. Am J Respir Crit Care Med 2013;187:347-365.

-2 Puhan MA, Gimeno-Santos E, Scharplatz M, Troosters T, Walters EH, Steurer J: Pulmonary rehabilitation following exacerbations of chronic obstructive pulmonary disease. Cochrane Database Syst Rev 2011:CD005305.

-3 Gloeckl R, Heinzelmann I, Baeuerle S, Damm E, Schwedhelm AL, Diril M, Buhrow D, Jerrentrup A, Kenn K: Effects of whole body vibration in patients with chronic obstructive pulmonary disease - a randomized controlled trial. Respir Med 2012;106:75-83.

-4 Lacasse Y, Goldstein R, Lasserson TJ, Martin S: Pulmonary rehabilitation for chronic obstructive pulmonary disease. Cochrane Database Syst Rev 2006:CD003793.

5 Behnke M, Taube C, Kirsten D, Lehnigk B, Jorres RA, Magnussen H: Home-based exercise is capable of preserving hospital-based improvements in severe chronic obstructive pulmonary disease. Respir Med 2000;94: 1184-1191.

6 6 Behnke M, Jorres RA, Kirsten D, Magnussen $\mathrm{H}$ : Clinical benefits of a combined hospital and home-based exercise programme over 18 months in patients with severe COPD. Monaldi Arch Chest Dis 2003;59:44-51.

7 Green RH, Singh SJ, Williams J, Morgan MD: A randomised controlled trial of four weeks versus seven weeks of pulmonary rehabilitation in chronic obstructive pulmonary disease. Thorax 2001;56:143-145.

8 Spruit MA, Singh SJ, Garvey C, et al: An official American Thoracic Society/European Respiratory Society statement: key concepts and advances in pulmonary rehabilitation. Am J Respir Crit Care Med 2013;188:e13-e64.

-9 Yoshimura K, Maekura R, Hiraga T, Miki K, Kitada S, Miki M, Tateishi Y, Mori M: Identification of three exercise-induced mortality risk factors in patients with COPD. COPD 2014;11:615-626.

10 de Sousa Pinto JM, Martín-Nogueras AM, Calvo-Arenillas JI, Ramos-González J: Clinical benefits of home-based pulmonary rehabilitation in patients with chronic obstructive pulmonary disease. J Cardiopulm Rehabil Prev 2014;34:355-359.
11 Rabe KF, Hurd S, Anzueto A, Barnes PJ, Buist SA, Calverley P, Fukuchi Y, Jenkins C, Rodriguez-Roisin R, van Weel C, Zielinski J: Global strategy for the diagnosis, management, and prevention of chronic obstructive pulmonary disease: GOLD executive summary. Am J Respir Crit Care Med 2007;176:532-555.

12 Brusasco V, Crapo R, Viegi G: Coming together: the ATS/ERS consensus on clinical pulmonary function testing (in French). Rev Mal Respir 2007;24:2S11-2S14.

13 ATS Committee on Proficiency Standards for Clinical Pulmonary Function Laboratories: ATS statement: guidelines for the six-minute walk test. Am J Respir Crit Care Med 2002; 166:111-117.

14 Ries AL: Minimally clinically important difference for the UCSD Shortness of Breath Questionnaire, Borg Scale, and Visual Analog Scale. COPD 2005;2:105-110.

15 Jones PW, Harding G, Berry P, Wiklund I, Chen WH, Kline LN: Development and first validation of the COPD Assessment Test. Eur Respir J 2009;34:648-654.

16 Mahler DA, Wells CK: Evaluation of clinical methods for rating dyspnea. Chest 1988;93: 580-586.

17 Puhan MA, Chandra D, Mosenifar Z, Ries A, Make B, Hansel NN, Wise RA, Sciurba F: The minimal important difference of exercise tests in severe COPD. Eur Respir J 2011;37:784790 .

18 Altenburg WA, de Greef MH, ten Hacken $\mathrm{NH}$, Wempe JB: A better response in exercise capacity after pulmonary rehabilitation in more severe COPD patients. Respir Med 2012;106:694-700.

19 von Leupoldt A, Hahn E, Taube K, SchubertHeukeshoven S, Magnussen H, Dahme B: Effects of 3-week outpatient pulmonary rehabilitation on exercise capacity, dyspnea, and quality of life in COPD. Lung 2008; 186 :387391.

20 Troosters T, Probst VS, Crul T, Pitta F, Gay an-Ramirez G, Decramer M, Gosselink R: Resistance training prevents deterioration in quadriceps muscle function during acute exacerbations of chronic obstructive pulmonary disease. Am J Respir Crit Care Med 2010;181: 1072-1077.

21 Greulich T, Nell C, Koepke J, Fechtel J, Franke M, Schmeck B, Haid D, Apelt S, Filipovic S, Kenn K, Janciauskiene S, Vogelmeier C, Koczulla AR: Benefits of whole body vibration training in patients hospitalised for COPD exacerbations - a randomized clinical trial. BMC Pulm Med 2014;14:60.
22 Kon SS, Canavan JL, Jones SE, Nolan CM, Clark AL, Dickson MJ, Haselden BM, Polkey MI, Man WD: Minimum clinically important difference for the COPD Assessment Test: a prospective analysis. Lancet Respir Med 2014; 2:195-203.

23 Cazzola M, MacNee W, Martinez FJ, Rabe KF, Franciosi LG, Barnes PJ, Brusasco V, Burge PS, Calverley PM, Celli BR, Jones PW, Mahler DA, Make B, Miravitlles M, Page CP, Palange P, Parr D, Pistolesi M, Rennard SI, Rutten-van Mölken MP, Stockley R, Sullivan SD, Wedzicha JA, Wouters EF: Outcomes for COPD pharmacological trials: from lung function to biomarkers. Eur Respir J 2008;31:416-469.

24 Stav D, Raz M, Shpirer I: Three years of pulmonary rehabilitation: inhibit the decline in airflow obstruction, improves exercise endurance time, and body-mass index, in chronic obstructive pulmonary disease. BMC Pulm Med 2009;9:26

25 Garrod R, Marshall J, Barley E, Jones PW: Predictors of success and failure in pulmonary rehabilitation. Eur Respir J 2006;27:788794.

26 Zanini A, Chetta A, Gumiero F, Della Patrona S, Casale S, Zampogna E, Aiello M, Spanevello A: Six-minute walking distance improvement after pulmonary rehabilitation is associated with baseline lung function in complex COPD patients: a retrospective study. Biomed Res Int 2013;2013:483162.

27 Vagaggini B, Costa F, Antonelli S, De Simone C, De Cusatis G, Martino F, Santerini S, Paggiaro P: Clinical predictors of the efficacy of a pulmonary rehabilitation programme in patients with COPD. Respir Med 2009;103: 1224-1230.

28 van Ranst D, Otten H, Meijer JW, van 't Hul AJ: Outcome of pulmonary rehabilitation in COPD patients with severely impaired health status. Int J Chron Obstruct Pulmon Dis 2011; 6:647-657.

29 Bolton CE, Bevan-Smith EF, Blakey JD, Crowe P, Elkin SL, Garrod R, Greening NJ, Heslop K, Hull JH, Man WD, Morgan MD, Proud D, Roberts CM, Sewell L, Singh SJ, Walker PP, Walmsley S: British Thoracic Society guideline on pulmonary rehabilitation in adults. Thorax 2013;68(suppl 2):ii1-ii30.

30 Vestbo J, Vogelmeier C, Small M, Higgins V: Understanding the GOLD 2011 Strategy as applied to a real-world COPD population. Respir Med 2014;108:729-736. 